\title{
Article \\ Fortified Cold-Pressed Oils: The Effect on Sensory Quality and Functional Properties
}

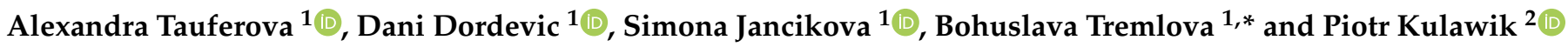 \\ 1 Department of Plant Origin Food Sciences, Faculty of Veterinary Hygiene and Ecology, \\ University of Veterinary Sciences Brno, Palackeho tr. 1946/1, 61242 Brno, Czech Republic; \\ tauferovaa@vfu.cz (A.T.); dordevicd@vfu.cz (D.D.); jancikovas@vfu.cz (S.J.) \\ 2 Department of Animal Product Technology, Faculty of Food Technology, University of Agriculture, \\ 04-218 Krakow, Poland; kulawik.piotr@gmail.com \\ * Correspondence: TREMLOVAB@vfu.cz
}

Citation: Tauferova, A.; Dordevic, D.; Jancikova, S.; Tremlova, B.; Kulawik, P. Fortified Cold-Pressed Oils: The Effect on Sensory Quality and Functional Properties. Separations 2021, 8, 55. https://doi.org/ 10.3390 /separations 8050055

Academic Editor: Natalia Drabińska and Marta Ferreiro-González

Received: 4 March 2021

Accepted: 16 April 2021

Published: 21 April 2021

Publisher's Note: MDPI stays neutral with regard to jurisdictional claims in published maps and institutional affiliations.

Copyright: (c) 2021 by the authors. Licensee MDPI, Basel, Switzerland. This article is an open access article distributed under the terms and conditions of the Creative Commons Attribution (CC BY) license (https:/ / creativecommons.org/licenses/by/ $4.0 /)$.

\begin{abstract}
The aim of this study was to monitor sensory quality, stability, selected nutritionally interesting properties and their changes in cold-pressed oil blends after fortification with chia and sesame seeds and seed oils during repeated thermal treatments. Rapeseed (cv. Sidney) and sunflower (cv. Velox) seeds from the Czech Republic were used to produce cold-pressed oils, which were fortified with chia and sesame seeds and seed oils in the concentrations of $1 \%$ and $5 \%$. In all oil blends, sensory evaluation (quantitative descriptive analysis and hedonic analysis) and chemical analyses (oxidation degree, hydrolytic stability, chlorophyll and carotenoid content) were carried out in order to perform separation of samples degraded by thermal treatment. Assessors representing consumers were able to differentiate between individual thermal treatments from the viewpoint of pleasantness. Interestingly, the overall pleasantness of all fortified oil samples was still acceptable until the second thermal treatment. On the other hand, the results of the study emphasized the problematic oxidation degree of cold-pressed oil blends. The fortification of cold-pressed oils with chia and sesame seeds and oils did not unambiguously lead to better stability during thermal treatment. The application of elevated temperatures during the culinary use of these types of products should be limited to only one thermal treatment since sensory and chemical changes occur after repeated heating.
\end{abstract}

Keywords: oxidized odor; oxidized taste; burnt taste; burnt odor; oxidation degree

\section{Introduction}

Rapeseed (Brassica napus) and sunflower (Helianthus annuus) belong to the most important oil crops cultivated worldwide, and cold-pressed rapeseed and sunflower oils are starting to be more popular among consumers, especially in Poland, Germany, Great Britain and France [1-5]. Rapeseed crop production represents $10 \%$ of worldwide oilseed production [6].

The technological process employed in the production of cold-pressed oil makes it nutritionally more acceptable as well as sensorially more interesting for some consumers $[7,8]$. Furthermore, in the case of many food commodities, consumers are searching for lessprocessed options, and cold-pressed oils are often perceived as healthier than refined vegetable oils. Some studies indicate that cold-pressed oils such as virgin olive oil, coldpressed rapeseed oil or Moringa oleifera seed oil could also be a suitable option for culinary applications using elevated temperatures, even during frying [3,9,10].

Despite unquestionable benefits, cold-pressed oils present a major issue on two fronts, i.e., a decrease of their (1) stability and (2) sensory quality during storage and thermal treatment [6]. Oil stability is one of the most important factors that affect the oil quality since instable oils have an undesirable taste and flavor $[3,11]$. One way to improve the stability of oils is by blending with ingredients containing high antioxidant levels [12]. To satisfy the consumer's demands, oil blending is increasingly used in the food industry, and 
attractive new products promising improved characteristics are introduced to the market. These are, in particular, extra virgin olive oils with herbs or spices called condiments, which gain considerable attention from consumers due to added nutritional and sensory benefit. Nevertheless, they are mainly not intended for thermal processing. Products of this type are predominantly used as salad dressings, but they could possibly also be used as alternatives for culinary operations applying higher temperature. Though, in some conditions, this type of processing can negatively influence the product stability as well as its sensory and nutritional profile [13,14].

Seeds are often used for the fortification since many of them contain higher amounts of nutritionally valued components [15]. Chia (Salvia hispanica L.) seeds are a suitable option to be used as an ingredient for fortification due to their favorable nutritional profile and high level of antioxidants. These include phenolic compounds, especially myricetin, quercetin, kaempferol and chlorogenic acid. Additionally, chia seeds contain carotenoids, tocopherols and phytosterols [16]. Sesame (Sesamum indicum) seeds are another option. They stand out among the raw materials for the production of vegetable oils due to the presence of sesamol and their high stability at higher temperatures [17]. In addition to sesamol, other lignans, especially sesamin and sesaminol and tocopherols contribute to the antioxidant potential of sesame $[18,19]$. The aim of this study was to monitor the stability, sensory quality, selected nutritionally interesting properties and their changes in cold-pressed blends of rapeseed and sunflower oils after fortification with chia and sesame seeds and seed oils during repeated thermal treatments.

\section{Materials and Methods}

\subsection{Materials}

The sunflower and rapeseed oils used in this study were of the cultivars Velox and Sidney, respectively. The extraction was performed on an industrial scale by a local producer in the Czech Republic. The oil yield, prepared by screw press and filtered through a non-woven filter, was $30 \%$.

Organic-quality seeds (chia and sesame) and oils (chia and sesame cold-pressed oils) purchased from the local market were added to cold-pressed sunflower and rapeseed oils at $1 \%$ and $5 \%$ concentrations. The seeds were crushed in a mortar immediately before mixing with the oils. The samples prepared for the experiment are shown in Table 1.

Table 1. Analyzed samples of fortified oil mixtures.

\begin{tabular}{cc}
\hline Sample & Mixture \\
\hline S & Sunflower oil (Velox) \\
R & Rapeseed oil (Sidney) \\
Sss1 & Sunflower oil + 1\% sesame seeds \\
Sss5 & Sunflower oil + 5\% sesame seeds \\
Rss1 & Rapeseed seed oil + 1\% sesame seeds \\
Rss5 & Rapeseed seed oil + 5\% sesame seeds \\
Schs1 & Sunflower oil + 1\% chia seeds \\
Schs5 & Sunflower oil + 5\% chia seeds \\
Rchs1 & Rapeseed oil + 1\% chia seeds \\
Rchs5 & Rapeseed oil + 5\% chia seeds \\
Sso1 & Sunflower oil + 1\% sesame oil \\
Sso5 & Sunflower oil + 5\% sesame oil \\
Rso1 & Rapeseed oil + 1\% sesame oil \\
Rso5 & Rapeseed oil $+5 \%$ sesame oil \\
Scho1 & Sunflower oil + 1\% chia oil \\
Scho5 & Sunflower oil + 5\% chia oil \\
Rcho1 & Rapeseed oil + 1\% chia oil \\
Rcho5 & Rapeseed oil + 5\% chia oil \\
\hline
\end{tabular}




\subsection{Methods}

\subsubsection{Thermal Treatment of the Fortified Oils}

The prepared samples underwent three cycles of repeated heating in a Unox Elena convection oven (Unox, Cadoneghe, Italy,). Briefly, $100 \mathrm{~mL}$ of each sample was heated in a glass vessel with a total volume of $1000 \mathrm{~mL}$. Each thermal treatment took $10 \mathrm{~min}$ at $220^{\circ} \mathrm{C}$ and was followed by 20 min of cooling.

\subsubsection{Sensory Analyses of the Fortified Oils}

Sensory analyses were performed at the Department of Plant Origin Foodstuffs Hygiene and Technology, Faculty of Veterinary Hygiene and Ecology, University of Veterinary and Pharmaceutical Sciences Brno, the Czech Republic. Both quantitative descriptive analysis and hedonic testing were performed on fortified cold-pressed rapeseed and sunflower oils prior to and after the thermal treatment. The aim of the sensory analysis was to determine whether the trained panelists or the recruited assessors were able to perceive any statistically significant differences between the control samples prior to thermal treatment and the samples of fortified oils after individual, model thermal treatments. Simultaneously, we wanted to describe the acceptability or pleasantness of the thermally treated samples as perceived by recruited assessors representing consumers.

\section{Quantitative Descriptive Analysis}

Quantitative descriptive analysis of the fortified oil samples was performed by the trained panel consisting of academic staff and the students of the Department of Plant Origin Food Sciences. All the panelists had previous experience with sensory analysis of various food commodities and familiarity with cold-pressed oils. The average age of eight panelists (six women and two men) was 30.5 years. A session aimed at panel discussion on the most cited descriptors of cold-pressed rapeseed and sunflower oils $[5,20]$ was performed in order to select those that best characterize the product and to eliminate those that were not perceived by most panelists. After the discussion and selection of the descriptors, a training session of the selected oil descriptors' intensity scale method preceded the quantitative descriptive analysis of oil samples. During the training session, reference samples were provided to each panelist to form a sensory memory.

Selected attributes are listed in Table 2. All attributes were quantified using a 9-point category ordinal scale with described extreme from 1 (no perception) to 9 (the highest intensity).

Table 2. Attributes for quantitative descriptive analysis of fortified cold-pressed rapeseed and sunflower oils and their definitions.

\begin{tabular}{cc}
\hline Attribute & Definition \\
\hline Appearance & \\
Yellow color & Intensity of yellow color \\
Aroma/odor & \\
Original aroma & Intensity of natural aroma associated with rapeseed or \\
Oxidized odor & sunflower oil depending on the assessed matrices \\
Burnt odor & Intensity of odor associated with oxidized oil \\
Flavor & Intensity of odor associated with burnt oil \\
Original flavor & Intensity of natural flavor associated with rapeseed or \\
Oxidized flavor & sunflower oil depending on the assessed matrices \\
Burnt flavor & Intensity of flavor associated with oxidized oil \\
& Intensity of flavor associated with burnt oil \\
\hline
\end{tabular}

Before each session, the panel was calibrated with respect to the intensities of the perceived sensory attributes by evaluating the same standard reference samples-coldpressed rapeseed and sunflower oil without any addition or heating. Moreover, samples 
of oxidized and burnt oils were available for attuning the sensory perception criteria of panelists. Samples were presented in a simultaneous presentation scheme [21], served in clear plastic cups of $20 \mathrm{~mL}$ volume identified by three-digit numerical codes and assessed at $28 \pm 2{ }^{\circ} \mathrm{C}$. In all, seven oil samples were served per session, and panelists attended one session per day. Clean still water and white bread were provided as a neutralizer.

\section{Hedonic Analysis}

Trained panelists ( $\mathrm{n}=22$; aged from 21 to 48 years old, 18 women and 4 men) consisting of 22 students and employees of the Faculty of Veterinary Hygiene and Ecology were recruited for the hedonic analysis. Pleasantness of appearance, aroma, flavor and overall pleasantness were evaluated using the 9-point category ordinal hedonic scale $(1=$ dislike extremely, $5=$ neither like nor dislike, $9=$ like extremely).

The hedonic analysis was performed in a complete block in 10 sessions $(7$ samples per each session). The oils were presented simultaneously in clear plastic cups of $20 \mathrm{~mL}$ volume identified by three-digit numerical codes.

\subsubsection{Chemical Analyses of the Fortified Oils}

The following analyses were performed on experimentally produced samples:

The peroxide value was determined according to ISO 3960:2017 [22]. Briefly, $5 \mathrm{~g}$ of oil was weighed and mixed with $30 \mathrm{~mL}$ of chloroform and glacial acetic acid (ratio 2:3). The mixture was shaken for $1 \mathrm{~min}$, then the $30 \mathrm{~mL}$ of distilled water and $5 \mathrm{~mL}$ of starch solution were added. After this, the samples were titrated with $0.01 \mathrm{M} \mathrm{Na}_{2} \mathrm{~S}_{2} \mathrm{O}_{3}$. In the blank sample, water was added instead of oil. The peroxide value was calculated using the following formula:

$\mathrm{PV}$ (milliequivalents of active oxygen $/ \mathrm{kg}$ oil; mekv. $\left.\left.\mathrm{O}_{2} / \mathrm{kg}\right)=10 \times\left(\mathrm{V}_{\mathrm{Na2S2O} 3}\right)-\mathrm{V}_{\text {blank }}\right) / \mathrm{W}$

where $\mathrm{V}_{\mathrm{Na} 2 \mathrm{~S}_{2} \mathrm{O} 3}$ - volume of $\mathrm{Na}_{2} \mathrm{~S}_{2} \mathrm{O}_{3}$ used for the titration of the sample $(\mathrm{mL}), \mathrm{V}_{\text {blank }}$ volume of $\mathrm{Na}_{2} \mathrm{~S}_{2} \mathrm{O}_{3}$ used for the titration of the blank sample $(\mathrm{mL}), \mathrm{W}$-amount of the sample (g).

Free fatty acids (FFAs) were determined according to ISO 660:2009 [23]. Briefly, $5 \mathrm{~g}$ of oil was mixed with $50 \mathrm{~mL}$ of diethylether, $1 \mathrm{~mL}$ of phenolphthalein solution was added, and the sample was titrated with $0.1 \mathrm{M} \mathrm{KOH}$. The free fatty acid value was calculated using the following formula:

$$
\mathrm{FFA}=(56.11 \times \mathrm{V} \times \mathrm{c} / \mathrm{m}) \times 10
$$

where $\mathrm{V}$-amount of the used $\mathrm{KOH}(\mathrm{mL}), \mathrm{c}$ - concentration of the $\mathrm{KOH}(0.1 \mathrm{M}), \mathrm{m}$ - amount of the sample (g).

Chlorophyll and carotenoid content was analyzed according to Kraljic et al. [24] using the spectrophotometric method. The absorbance was measured at 670, 630, 710 and $445 \mathrm{~nm}$. The following formulas were used:

$$
\begin{gathered}
\text { chlorophyll content }(\mathrm{mg} / \mathrm{kg})=34.53\left[\mathrm{~A}_{670}-0.5\left(\mathrm{~A}_{630}+\mathrm{A}_{710}\right)\right] \\
\text { carotenoid content }(\mathrm{mg} / \mathrm{kg})=\left[383 \times \mathrm{A}_{445}\right] / 10^{*}
\end{gathered}
$$

*10: cuvette width in $\mathrm{mm}$.

\subsubsection{Statistical Analysis}

The experimental design in the sensory analyses was a complete block design. Statistical analyses of sensory data were performed using the SensoMineR package for R software (The R Foundation for Statistical Computing, Austria). Principal component analysis (PCA) was selected for sensory data evaluation as well as for complex data evaluation from both chemical and sensory analyses. For processing the results of chemical analyses, statistical significance at $p<0.05$ was evaluated by one-way ANOVA (analysis of variance) and parametric Tukey post hoc test (in the case when Levene's test showed equal variances 
$p>0.05$ ) and nonparametric Games-Howell post hoc test (in the case when Levene's test showed unequal variances $p<0.05$ ) for finding differences within groups.

\section{Results and Discussion}

\subsection{Sensory Quality of the Fortified Oils}

\subsubsection{Quantitative Descriptive Analysis}

The results of the quantitative descriptive analysis of fortified cold-pressed rapeseed and sunflower oils prior to and after individual thermal treatments are shown in Figure 1. The position of the ellipses representing groups of fortified oils indicates that panelists were able to perceive many statistically significant $(p<0.05)$ differences between oil groups after individual thermal treatments. However, based on the results of sensory analysis, it was not possible to determine a clear trend comparing the effect of chia and sesame addition in the form of seeds and oils since the panelists were not able to perceive statistically significant $(p<0.05)$ differences in sensory descriptors for $1 \%$ and $5 \%$ addition.

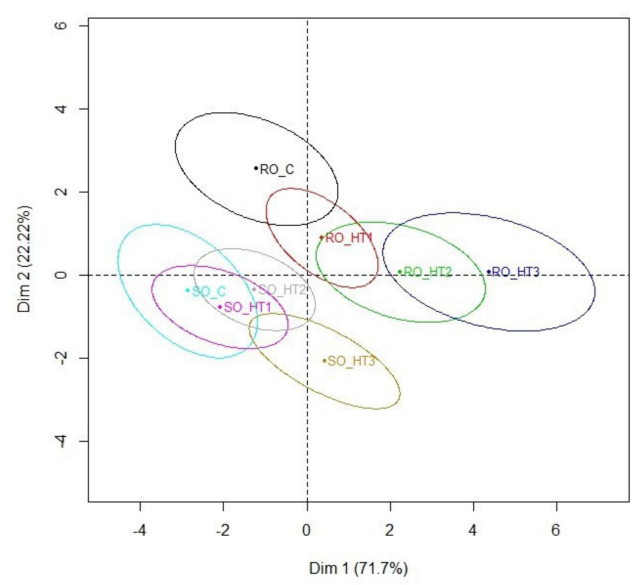

(a)

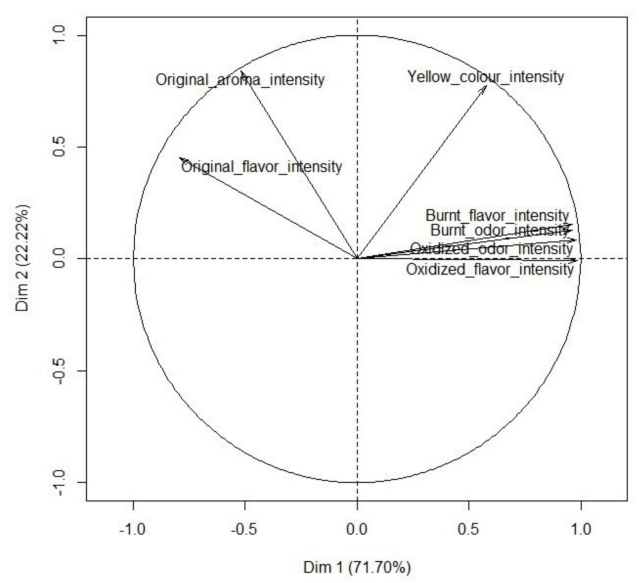

(b)

Figure 1. The results of PCA of the quantitative descriptive analysis of fortified oils before and after heat treatments: (a) Confidence ellipses for the mean points (RO_C, rapeseed oil control; RO_HT1, rapeseed oil samples after 1st heat treatment; RO_HT2, rapeseed oil samples after 2nd heat treatment; RO_HT3, rapeseed oil samples after 3rd heat treatment; SO_C, sunflower oil control; SO_HT1, sunflower oil after 1st heat treatment; SO_HT2, sunflower oil after 2nd heat treatment; SO_HT3, sunflower oil after 3rd heat treatment). (b) Variables factor map.

In the case of rapeseed oils, the original flavor intensity decreased significantly $(p<0.05)$ after the second thermal treatment as did the original aroma intensity. The study focused on changes in the volatile profile of vegetable oils during short-term deepfrying showed that the content of terpenes responsible for cold-pressed oil aroma decreased considerably, from $17.4 \%$ in the unheated to $3.02 \%$ in oils after $20 \mathrm{~min}$ of deep-frying at $180^{\circ} \mathrm{C}$ [23]. Oxidized odor intensity, as a negatively evaluated descriptor, was already slightly increased after the first thermal treatment. The other negatively evaluated descriptor, burnt odor, increased significantly $(p<0.05)$ only after the third thermal treatment. Oxidized flavor was significantly $(p<0.05)$ more intense after the second thermal treatment, and burnt flavor increased significantly only after the third thermal treatment. Similarly, Multari et al. [25] found that aldehydes, as oxidation products developed during deepfrying, increased from $15.9 \%$ in unheated oil to $52.7 \%$ after $20 \mathrm{~min}$ of deep-frying at $180{ }^{\circ} \mathrm{C}$.

As shown in Table 3, there was no statistically significant $(p>0.05)$ difference between the control group of fortified rapeseed oil samples without any thermal treatment and the group of fortified rapeseed oil samples that were subjected to the first thermal treatment, but there was statistically significant $(p<0.05)$ difference between the control group and the group of fortified rapeseed oil samples after the second thermal treatment. There was no perceived shift in yellow color intensity in any of the groups of both fortified 
rapeseed and sunflower oils prior to and in between the individual thermal treatments. Color change is used as an indicator for rapid monitoring of frying oil quality by the food industry, and it occurs as a consequence of several processes: (a) the development of pigments during oxidation of phenolic antioxidants, (b) oxidation and polymerization of unsaturated fatty acids and (c) the increase of linolenic fatty acids. The darkening of color is a useful phenomenon since it can prevent the use of oil that has undergone excessive deterioration [26]. Our fortified oil samples showed no visible color changes after all three experimental thermal treatments, pointing out that no extensive detrimental chemical changes in oil nutritional quality occurred during the experiment. Similarly, there was no significant $(p>0.05)$ increase in instrumentally measured lightness (L value) in coconut-sesame oil blends during frying, although some blends showed decreased red color, which may be attributed to the loss of natural antioxidants [27].

Table 3. Matrix with the $p$-values of the Hotelling's $T^{2}$ tests for each pair of fortified oil groups (quantitative descriptive analysis).

\begin{tabular}{ccccccccc}
\hline & RO_C & RO_HT1 & RO_HT2 & RO_HT3 & SO_C & SO_HT1 & SO_HT2 & SO_HT3 \\
\hline RO_C & 1.00 & 0.09 & $p<0.01$ & $p<0.01$ & $p<0.01$ & $p<0.01$ & $p<0.01$ & $p<0.01$ \\
RO_HT1 & 0.09 & 1.00 & 0.17 & $p<0.01$ & $p<0.01$ & $p<0.01$ & $p<0.01$ & $p<0.01$ \\
RO_HT2 & $p<0.01$ & 0.17 & 1.00 & 0.26 & $p<0.01$ & $p<0.01$ & $p<0.01$ & $p<0.01$ \\
RO_HT3 & $p<0.01$ & $p<0.01$ & 0.26 & 1.00 & $p<0.01$ & $p<0.01$ & $p<0.01$ & $p<0.01$ \\
SO_C & $p<0.01$ & $p<0.01$ & $p<0.01$ & $p<0.01$ & 1.00 & 0.70 & 0.16 & $p<0.01$ \\
SO_HT1 & $p<0.01$ & $p<0.01$ & $p<0.01$ & $p<0.01$ & 0.70 & 1.00 & 0.35 & $p<0.05$ \\
SO_HT2 & $p<0.01$ & $p<0.01$ & $p<0.01$ & $p<0.01$ & 0.16 & 0.35 & 1.00 & $p<0.05$ \\
SO_HT3 & $p<0.01$ & $p<0.01$ & $p<0.01$ & $p<0.01$ & $p<0.01$ & $p<0.05$ & $p<0.05$ & 1.00 \\
\hline
\end{tabular}

Statistically significant differences between the groups are emphasized in green. RO_C, rapeseed oil control RO_HT1, rapeseed oil samples after 1st heat treatment; RO_HT2, rapeseed oil samples after 2nd heat treatment; RO_HT3, rapeseed oil samples after 3rd heat treatment; SO_C, sunflower oil control; SO_HT1, sunflower oil after 1st heat treatment; SO_HT2, sunflower oil after 2nd heat treatment; SO_HT3, sunflower oil after 3rd heat treatment.

In the case of sunflower oils, the original flavor intensity did not change during the experimental thermal treatments, only the original aroma intensity decreased slightly after the third thermal treatment. This could be due to the fact that unheated, cold-pressed sunflower oil is originally high in terpenes, although most of them were lost upon deepfrying [25].

When speaking about negatively evaluated descriptors, neither oxidized odor nor burnt odor intensity increased significantly $(p<0.05)$ during the thermal treatments. Only oxidized flavor was significantly $(p<0.05)$ more intense after the third thermal treatment. Similarly, a study focused on the sensory parameters of coconut oil blends with sesame oil during frying showed that oxidized odor was not perceived in any of the blends during frying [27]. As shown in Table 3, there was no statistically significant $(p>0.05)$ difference between the control group of fortified sunflower oil samples without any thermal treatment and the group of fortified sunflower oil samples that were subjected to the first and the second thermal treatments. Only the group of fortified sunflower oil samples after the third thermal treatment was significantly different from all the other groups of sunflower oil samples. This is interesting, because cold-pressed sunflower oil without any fortification generally exhibits a very low oxidation stability index and has low resistance to oxidative-induced degradation [28]. Despite this fact, sunflower oil showed lower levels of unpleasant off-flavors. It showed the lowest levels of unpleasant off-flavors among six different unfortified vegetable oils including rapeseed oil [29]. These findings are in accordance with our results.

\section{Sensory Analysis as a Separation Method}

Separation methods are usually physico-chemical methods consisting of separation of the individual components of a mixture in order to obtain pure components. Their main goal is to answer questions about what substances are in the sample, i.e., its qualitative composition, or, on a deeper level, what is the amount of these substances in the sample, 
i.e., quantitative composition. Sensory analysis has been defined as a scientific method used to evoke, measure, analyze and interpret responses to products as perceived through human senses. It attempts to isolate the sensory properties of foods themselves and allows to distinguish different products [30]. The field of sensory evaluation is growing rapidly and by means of sensory analysis, it is possible to detect groups of various substances in analyzed products, which was previously performed mostly by means of gas chromatography. This is possible especially thanks to the expert panelists and elaborated protocols involving training sessions and reference materials. There are many efforts to increase the reliability and accuracy of sensory analyses in the research of edible oils to detect oxidized odor. One example of such effort is the formulation of artificial olfactory reference materials for virgin olive oil sensory evaluation [31]. Individual volatiles responsible for oxidized odor can be detected by gas chromatography, the mixture of volatiles contributing to the oxidized odor can also be detected by means of sensory analysis allowing separation of the rancid samples from those that are still sensorially acceptable. Moreover, Wiking et al. [32] proved high correlation between sensorially determined oxidized flavor and free fatty acids determined by chemical analyses and gas chromatography-mass spectrometry among others. They concluded that, today, many analytical techniques, including sensory analysis, are available for quantifying free fatty acids, giving important information regarding the rancid off-flavor.

\subsubsection{Hedonic Analysis}

The results of hedonic analysis of fortified cold-pressed rapeseed and sunflower oils prior to and after individual thermal treatments are shown in Figure 2.

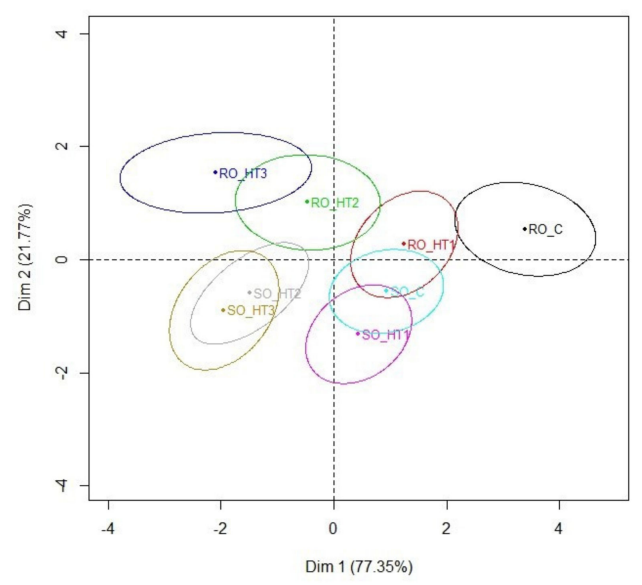

(a)

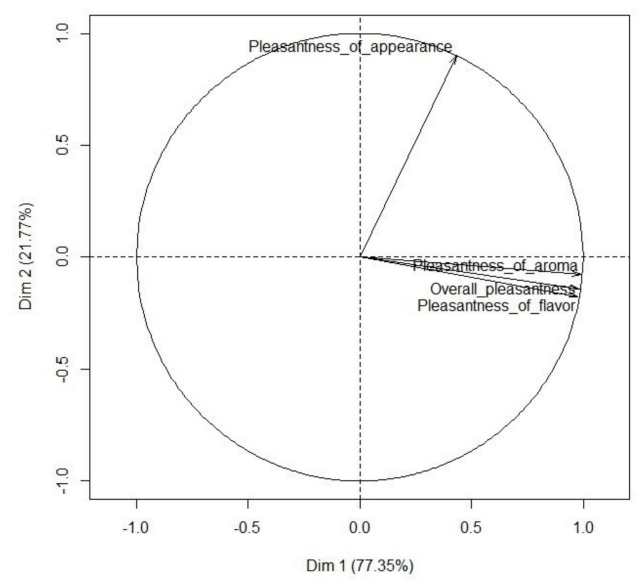

(b)

Figure 2. The results of PCA of hedonic analysis of oils before and after heat treatments: (a) Confidence ellipses for the mean points (RO_C, rapeseed oil control; RO_HT1, rapeseed oil samples after 1st heat treatment; RO_HT2, rapeseed oil samples after 2nd heat treatment; RO_HT3, rapeseed oil samples after 3rd heat treatment; SO_C, sunflower oil control; SO_HT1, sunflower oil after 1st heat treatment; SO_HT2, sunflower oil after 2nd heat treatment; SO_HT3, sunflower oil after 3rd heat treatment). (b) Variables factor map.

Some of the samples characterized by the same treatment formed distinct clusters showing that the assessors were able to differentiate between individual thermal treatments from the viewpoint of pleasantness. The position of the ellipses representing groups of fortified oils indicates that many statistically significant $(p<0.05)$ differences between the groups of oils after individual thermal treatments were perceived. Data on the sensory quality of various oils after thermal treatment conducted during cooking are scarce. One example of such a study is the experiment focused on the evaluation of flavor, taste, color and viscosity of deep-fried soybean oils in order to determine the oil disposal point [33]. In accordance with our results, the above-mentioned study showed that it is possible to 
apply sensory analysis to frying oil quality and that the sensory method could be sensitive to small differences in rancidity. Pleasantness of appearance did not change either in the case of fortified rapeseed or in sunflower oil samples during the thermal treatments. The obtained results of other studies also indicated that longer thermal treatment is necessary for the color changes to appear-either as discoloration or darkening [34,35]. Nevertheless, the appearance of rapeseed oil samples was considered as slightly more attractive by assessors as it reached the value 7 (median) throughout the whole experiment, whereas the median of sunflower oil samples was stable at value 6.

In the case of rapeseed oils, aroma pleasantness decreased significantly $(p<0.05)$ and gradually after each thermal treatment. The same trends were noticed in flavor pleasantness and overall pleasantness. However, the overall pleasantness of rapeseed oil samples was still acceptable until the third thermal treatment as the median of the data obtained for this descriptor was 6 on the 9-point scale ( $1=$ dislike extremely, $5=$ neither like nor dislike, $9=$ like extremely). It should be emphasized that sensory qualities are often more important for the majority of consumers than nutritional value [36]. As shown in Table 4, assessors perceived statistically significant $(p<0.05)$ differences between all fortified rapeseed oil groups except between the samples after the second and the third thermal treatment.

Table 4. Matrix with the $p$-values of the Hotelling's $\mathrm{T}^{2}$ tests for each pair of fortified oil groups (hedonic analysis).

\begin{tabular}{ccccccccc}
\hline & RO_C & RO_HT1 & RO_HT2 & RO_HT3 & SO_C & SO_HT1 & SO_HT2 & SO_HT3 \\
\hline RO_C & 1.00 & $p<0.05$ & $p<0.01$ & $p<0.01$ & $p<0.01$ & $p<0.01$ & $p<0.01$ & $p<0.01$ \\
RO_HT1 & $p<0.05$ & 1.00 & $p<0.05$ & $p<0.01$ & 0.32 & $p<0.05$ & $p<0.01$ & $p<0.01$ \\
RO_HT2 & $p<0.01$ & $p<0.05$ & 1.00 & 0.10 & $p<0.01$ & $p<0.01$ & $p<0.05$ & $p<0.01$ \\
RO_HT3 & $p<0.01$ & $p<0.01$ & 0.10 & 1.00 & $p<0.01$ & $p<0.01$ & $p<0.01$ & $p<0.01$ \\
SO_C & $p<0.01$ & 0.32 & $p<0.01$ & $p<0.01$ & 1.00 & 0.30 & $p<0.01$ & $p<0.01$ \\
SO_HT1 & $p<0.01$ & $p<0.05$ & $p<0.01$ & $p<0.01$ & 0.30 & 1.00 & $p<0.01$ & $p<0.01$ \\
SO_HT2 & $p<0.01$ & $p<0.01$ & $p<0.05$ & $p<0.01$ & $p<0.01$ & $p<0.01$ & 1.00 & 0.76 \\
SO_HT3 & $p<0.01$ & $p<0.01$ & $p<0.01$ & $p<0.01$ & $p<0.01$ & $p<0.01$ & 0.76 & 1.00 \\
\hline
\end{tabular}

Statistically significant differences between the groups are emphasized in green. RO_C, rapeseed oil control RO_HT1, rapeseed oil samples after 1st heat treatment; RO_HT2, rapeseed oil samples after 2nd heat treatment; RO_HT3, rapeseed oil samples after 3rd heat treatment; SO_C, sunflower oil control; SO_HT1, sunflower oil after 1st heat treatment; SO_HT2, sunflower oil after 2nd heat treatment; SO_HT3, sunflower oil after 3rd heat treatment.

In the case of sunflower oils, both descriptors (aroma pleasantness and flavor pleasantness) decreased significantly $(p<0.05)$ only after the second thermal treatment, and the overall pleasantness followed the same trend. The overall pleasantness of sunflower oil samples was perceived as acceptable until the second thermal treatment as the median of the data obtained for this descriptor was 6 on the 9-point scale, and after the next consecutive thermal treatment, it dropped to 5. The comparison of fortified rapeseed and sunflower oil samples indicated that rapeseed oil's sensory quality changed gradually during the experimental thermal treatments, whereas sunflower oil was more stable in its sensory quality. This is in accordance with the study performed by $\mathrm{Xu}$ et al. [29], which also used sensory evaluation by a 9-point hedonic scale to compare the frying performance of different vegetable oils. Their results showed that sunflower oil was quite stable in sensory quality during the thermal treatment and reached the highest levels of taste acceptability and overall quality among six unfortified vegetable oils, though it performed significantly worse in free fatty acid content and total polar compounds.

As is clearly visible both from Figure 2 and Table 4, assessors perceived statistically significant $(p<0.05)$ differences between the control group and the groups of fortified sunflower oil samples after the second and the third thermal treatments and also between the group of fortified sunflower oil samples after the first thermal treatment and the groups of sunflower oils after the second and the third thermal treatments. The pleasantness of flavor and aroma, but not the pleasantness of appearance, were highly correlated to the overall pleasantness $(p<0.05)$ of fortified cold-pressed oils. 


\subsection{Chemical Characterization of Experimentally Fortified Oils}

The oxidation degree of oil samples (sunflower and rapeseed cold-pressed oil) with and without the addition of seeds and oils is shown in Table 5.

Table 5. Oxidation degree of fortified oil samples after repeated cycles of heating.

\begin{tabular}{|c|c|c|c|c|}
\hline Sample & $\begin{array}{l}\text { Without Heating } \\
\left.\text { (mekv. } \mathrm{O}_{2} / \mathrm{kg}\right)\end{array}$ & $\begin{array}{l}\text { 1st Heating } \\
\left(\mathrm{mekv} \mathrm{O}_{2} / \mathrm{kg}\right)\end{array}$ & $\begin{array}{c}\text { 2nd Heating } \\
\left(\mathrm{mekv} \mathrm{O}_{2} / \mathrm{kg}\right)\end{array}$ & $\begin{array}{l}\text { 3rd Heating } \\
\left(\mathrm{mekv} . \mathrm{O}_{2} / \mathrm{kg}\right)\end{array}$ \\
\hline$S$ & $1.30 \pm 0.20^{\mathrm{a}}$ & $27.14 \pm 0.65^{b}$ & $33.30 \pm 0.19^{b}$ & $37.78 \pm 0.35^{c}$ \\
\hline $\mathrm{R}$ & $2.76 \pm 0.20^{a}$ & $13.54 \pm 0.09^{b}$ & $12.95 \pm 0.02^{b}$ & $14.77 \pm 0.03^{c}$ \\
\hline Sss1 & $9.78 \pm 0.12^{\mathrm{a}}$ & $21.30 \pm 0.58^{b}$ & $24.47 \pm 0.86^{b}$ & $25.77 \pm 1.96$ \\
\hline Sss5 & $10.90 \pm 0.03^{a}$ & $15.46 \pm 0.08^{b}$ & $19.05 \pm 0.15^{c}$ & $23.54 \pm 0.28^{d}$ \\
\hline Rss1 & $5.90 \pm 0.01^{\mathrm{a}}$ & $9.52 \pm 0.32^{\mathrm{a}}$ & $10.12 \pm 0.27^{\mathrm{a}}$ & $13.49 \pm 0.14^{b}$ \\
\hline Rss5 & $5.25 \pm 0.06^{\mathrm{a}}$ & $10.53 \pm 0.29^{b}$ & $11.93 \pm 0.28^{b}$ & $11.38 \pm 0.30^{b}$ \\
\hline Schs1 & $11.00 \pm 0.14^{\mathrm{a}}$ & $25.16 \pm 0.30^{b}$ & $27.21 \pm 1.20$ & $33.07 \pm 0.03^{c}$ \\
\hline Schs5 & $11.17 \pm 0.42^{\mathrm{a}}$ & $25.96 \pm 0.19^{b}$ & $27.50 \pm 0.38^{b}$ & $32.96 \pm 2.44$ \\
\hline Rchs1 & $5.59 \pm 0.00^{\mathrm{a}}$ & $10.97 \pm 0.28^{b}$ & $12.85 \pm 0.10^{b}$ & $14.88 \pm 0.20^{c}$ \\
\hline Rchs5 & $5.79 \pm 0.15^{\mathrm{a}}$ & $10.29 \pm 0.41^{b}$ & $12.76 \pm 0.24 b c$ & $15.24 \pm 0.42^{c}$ \\
\hline Sso1 & $4.09 \pm 0.00^{\mathrm{a}}$ & $25.17 \pm 0.34^{b}$ & $24.63 \pm 1.09 \mathrm{bc}$ & $33.12 \pm 0.11^{c}$ \\
\hline Sso5 & $27.79 \pm 0.01$ & $22.63 \pm 0.46^{\mathrm{a}}$ & $24.18 \pm 0.69$ & $29.52 \pm 0.24^{b}$ \\
\hline Rso1 & $3.45 \pm 0.15^{\mathrm{a}}$ & $11.00 \pm 0.15^{b c}$ & $12.34 \pm 0.05^{b}$ & $13.04 \pm 0.02^{\mathrm{c}}$ \\
\hline Rso5 & $6.29 \pm 0.14^{\mathrm{a}}$ & $12.20 \pm 0.09^{b}$ & $11.19 \pm 0.68$ & $13.45 \pm 0.10^{c}$ \\
\hline Scho1 & $24.77 \pm 0.12^{\mathrm{a}}$ & $25.80 \pm 0.11^{b}$ & $27.33 \pm 0.03^{c}$ & $25.74 \pm 0.07^{a}$ \\
\hline Scho5 & $21.14 \pm 0.43^{\mathrm{a}}$ & $24.21 \pm 0.43^{b}$ & $23.23 \pm 0.11$ & $22.04 \pm 0.40$ \\
\hline Rcho1 & $6.05 \pm 0.09^{a}$ & $10.90 \pm 0.01^{b}$ & $12.24 \pm 0.57$ & $13.52 \pm 0.53$ \\
\hline Rcho5 & $12.81 \pm 0.13^{a}$ & $8.35 \pm 0.28 \mathrm{bc}$ & $8.15 \pm 0.25^{b}$ & $9.86 \pm 0.18^{c}$ \\
\hline
\end{tabular}

Different letters $(\mathrm{a}, \mathrm{b}, \mathrm{c}, \mathrm{d})$ indicate statistically significant $(p<0.05)$ differences between unheated and heated samples.

Oxidation degree was measured by the content of hydroperoxides (primary products of oxidation). The gained results indicate the increase in oxidation processes after almost each heating cycle. The highest increases (over 30 mekv. $\mathrm{O}_{2} / \mathrm{kg}$ ) after three heating cycles were measured in following samples: $\mathrm{S}$ (the second heating), Schs1 (the third heating) and Sso1 (the third heating). It should be emphasized that many samples (S, Sss1, Schs1, Schs5, Sso1, Sso5, Scho1, Scho5) even after the first heating cycle had a peroxide value over 20 mekv. $\mathrm{O}_{2} / \mathrm{kg}$; the limit that is considered not suitable for human consumption since peroxide values between 20 to $40 \mathrm{mekv} . \mathrm{O}_{2} / \mathrm{kg}$ indicate the rancid taste of edible oils [37]. Our results clearly showed that the oxidation degree of rapeseed cold-pressed oils (both with and without fortification) was lower in comparison with that of sunflower oil samples. This finding is unambiguously supported by the obtained results for chlorophyll and carotenoid contents. It can be seen that cold-pressed rapeseed oils had higher chlorophyll and carotenoid content (Tables 7 and 8 ). These findings are supported by the fact that the oxidation degree of the oils is in negative correlation with their contents of $\beta$-carotene and chlorophyll $[38,39]$.

The hydrolytic stability of experimentally produced fortified cold-pressed oils is shown in Table 6.

Statistically significant $(p<0.05)$ differences between heating cycles were obtained only among the following samples: R, Rss1, Rch1 and Scho1. According to these results, it can be stated that both sunflower and rapeseed cold-pressed oils showed relatively constant hydrolytic stability since all samples (heated and not heated) had a free fatty acid content under $4.0 \mathrm{mg} \mathrm{KOH} / \mathrm{g}$ (the suggested limit for cold-pressed fats and oils) [40]. The increase of free fatty acids in oils occurs during storage (mainly not adequate storage: light exposure and high temperature) and heating. The formed free fatty acids are mainly changed to primary and secondary oxidation products [41-43]. 
Table 6. Hydrolytic stability of fortified oil samples after repeated cycles of heating.

\begin{tabular}{ccccc}
\hline Sample & $\begin{array}{c}\text { Without } \\
\text { Heating } \mathbf{( m g} \\
\text { KOH/g) }\end{array}$ & $\begin{array}{c}\text { 1st Heating } \mathbf{~ ( m g ~} \\
\text { KOH/g) }\end{array}$ & $\begin{array}{c}\text { 2nd Heating } \\
\text { (mg KOH/g) }\end{array}$ & $\begin{array}{c}\text { 3rd Heating } \\
\text { (mg KOH/g) }\end{array}$ \\
\hline S & $0.43 \pm 0.03$ & $0.58 \pm 0.04$ & $0.61 \pm 0.08$ & $0.53 \pm 0.04$ \\
R & $1.42 \pm 0.06^{\mathrm{a}}$ & $1.80 \pm 0.12$ & $2.03 \pm 0.02^{\mathrm{b}}$ & $1.87 \pm 0.12$ \\
Sss1 & $0.67 \pm 0.00^{\mathrm{a}}$ & $0.80 \pm 0.04$ & $0.61 \pm 0.00^{\mathrm{b}}$ & $0.67 \pm 0.00^{\mathrm{a}}$ \\
Sss5 & $0.84 \pm 0.08$ & $0.81 \pm 0.04$ & $0.83 \pm 0.08$ & $0.78 \pm 0.00$ \\
Rss1 & $1.93 \pm 0.04$ & $1.86 \pm 0.03^{\mathrm{a}}$ & $2.15 \pm 0.03^{\mathrm{b}}$ & $1.98 \pm 0.05$ \\
Rss5 & $2.19 \pm 0.08$ & $2.45 \pm 0.01$ & $2.02 \pm 0.04$ & $2.16 \pm 0.08$ \\
Schs1 & $0.36 \pm 0.04$ & $0.50 \pm 0.08$ & $0.50 \pm 0.08$ & $0.47 \pm 0.04$ \\
Schs5 & $0.50 \pm 0.08$ & $0.45 \pm 0.00$ & $0.45 \pm 0.00$ & $0.45 \pm 0.08$ \\
Rchs1 & $1.68 \pm 0.16$ & $1.73 \pm 0.08$ & $1.78 \pm 0.00^{\mathrm{a}}$ & $1.68 \pm 0.01^{\mathrm{b}}$ \\
Rchs5 & $1.68 \pm 0.16$ & $2.01 \pm 0.01$ & $1.78 \pm 0.17$ & $1.72 \pm 0.08$ \\
Sso1 & $0.36 \pm 0.04$ & $0.45 \pm 0.00$ & $0.50 \pm 0.08$ & $0.50 \pm 0.08$ \\
Sso5 & $0.42 \pm 0.04$ & $1.78 \pm 0.06$ & $1.73 \pm 0.09$ & $1.65 \pm 0.12$ \\
Rso1 & $1.29 \pm 0.08$ & $1.73 \pm 0.08$ & $1.79 \pm 0.08$ & $1.68 \pm 0.00$ \\
Rso5 & $1.68 \pm 0.00$ & $0.55 \pm 0.00$ & $0.58 \pm 0.04$ & $0.42 \pm 0.04$ \\
Scho1 & $0.50 \pm 0.00^{\mathrm{a}}$ & $0.45 \pm 0.16$ & $0.50 \pm 0.08$ & $0.39 \pm 0.00^{\mathrm{b}}$ \\
Scho5 & $0.50 \pm 0.08$ & $0.45 \pm 0.00$ & $0.64 \pm 0.04$ & $0.56 \pm 0.15$ \\
Rcho1 & $1.71 \pm 0.04$ & $1.57 \pm 0.16$ & $1.61 \pm 0.08$ & $1.89 \pm 0.22$ \\
Rcho5 & $1.71 \pm 0.04$ & $1.90 \pm 0.09$ & $1.74 \pm 0.04$ & $1.79 \pm 0.01$ \\
\hline
\end{tabular}

Different letters $(\mathrm{a}, \mathrm{b})$ indicate statistically significant $(p<0.05)$ differences between unheated and heated samples.

It is known that chlorophylls under certain conditions, such as under sunlight, can act as prooxidants and consequently increase the level of oxidation. This could be especially noticeable in cold-pressed plant oils since these types of edible oils contain higher amounts of chlorophyll [44]. Our results indicated significantly $(p<0.05)$ decreased chlorophyll contents in almost all evaluated samples (Table 7).

Table 7. Chlorophyll content in fortified oil samples after repeated cycles of heating.

\begin{tabular}{|c|c|c|c|c|}
\hline Sample & $\begin{array}{l}\text { Without Heating } \\
(\mathrm{mg} / \mathrm{kg})\end{array}$ & $\begin{array}{c}\text { 1st Heating } \\
(\mathrm{mg} / \mathrm{kg})\end{array}$ & $\begin{array}{l}\text { 2nd Heating } \\
\text { (mg/kg) }\end{array}$ & $\begin{array}{l}\text { 3rd Heating } \\
\qquad(\mathrm{mg} / \mathrm{kg})\end{array}$ \\
\hline$S$ & $2.53 \pm 0.04^{a}$ & $2.23 \pm 0.01^{b}$ & $2.08 \pm 0.01^{c}$ & $1.89 \pm 0.01^{\mathrm{d}}$ \\
\hline $\mathrm{R}$ & $47.00 \pm 0.10^{a}$ & $46.14 \pm 0.03^{b}$ & $44.89 \pm 0.13^{c}$ & $43.11 \pm 0.11^{d}$ \\
\hline Sss1 & $2.10 \pm 0.01$ & $2.11 \pm 0.33$ & $2.16 \pm 0.04$ & $1.86 \pm 0.12$ \\
\hline Sss5 & $2.06 \pm 0.01^{a}$ & $2.16 \pm 0.05^{\mathrm{a}}$ & $2.10 \pm 0.03^{a}$ & $1.90 \pm 0.06^{b}$ \\
\hline Rss1 & $46.25 \pm 0.02^{\mathrm{a}}$ & $45.73 \pm 0.22^{b}$ & $45.24 \pm 0.16^{\mathrm{c}}$ & $44.13 \pm 0.19^{d}$ \\
\hline Rss5 & $45.60 \pm 0.02^{\mathrm{a}}$ & $45.69 \pm 0.32^{\mathrm{a}}$ & $44.87 \pm 0.17^{b}$ & $43.24 \pm 0.21^{\mathrm{c}}$ \\
\hline Schs1 & $2.11 \pm 0.01^{\mathrm{a}}$ & $2.28 \pm 0.08^{a b}$ & $2.03 \pm 0.02^{b}$ & $1.73 \pm 0.00^{\mathrm{c}}$ \\
\hline Schs5 & $2.04 \pm 0.02^{\mathrm{a}}$ & $2.18 \pm 0.05^{\mathrm{a}}$ & $2.30 \pm 0.17$ & $1.84 \pm 0.05^{b}$ \\
\hline Rchs1 & $46.17 \pm 0.01^{a}$ & $45.68 \pm 0.14^{\mathrm{ab}}$ & $45.08 \pm 0.25^{b}$ & $43.87 \pm 0.08^{c}$ \\
\hline Rchs5 & $45.78 \pm 0.03^{a}$ & $45.64 \pm 0.12^{\mathrm{a}}$ & $44.49 \pm 0.20^{c}$ & $43.29 \pm 0.23^{b}$ \\
\hline Sso1 & $1.54 \pm 0.02^{\mathrm{a}}$ & $2.29 \pm 0.05^{b}$ & $2.18 \pm 0.03 b c$ & $1.86 \pm 0.13^{\mathrm{ac}}$ \\
\hline Sso5 & $2.62 \pm 0.02^{a}$ & $2.39 \pm 0.01^{c}$ & $2.29 \pm 0.06^{b c}$ & $2.20 \pm 0.02^{b}$ \\
\hline Rso1 & $42.16 \pm 0.03^{a}$ & $45.61 \pm 0.34^{b}$ & $44.64 \pm 0.03^{b}$ & $42.11 \pm 0.02^{a}$ \\
\hline Rso5 & $45.45 \pm 0.19^{a}$ & $43.66 \pm 1.22$ & $43.23 \pm 0.02^{b}$ & $40.86 \pm 0.04^{c}$ \\
\hline Scho1 & $2.36 \pm 0.03^{a}$ & $2.33 \pm 0.00^{a}$ & $2.09 \pm 0.04^{c}$ & $1.96 \pm 0.07^{b}$ \\
\hline Scho5 & $2.26 \pm 0.02^{a}$ & $2.19 \pm 0.01^{b}$ & $2.03 \pm 0.01^{c}$ & $1.88 \pm 0.04^{\mathrm{d}}$ \\
\hline Rcho1 & $46.08 \pm 0.04^{\mathrm{a}}$ & $45.16 \pm 0.06^{b}$ & $44.16 \pm 0.09^{c}$ & $42.81 \pm 0.23^{d}$ \\
\hline Rcho5 & $45.86 \pm 0.03^{a}$ & $43.44 \pm 0.20^{b}$ & $43.06 \pm 0.18^{b}$ & $42.10 \pm 0.18^{c}$ \\
\hline
\end{tabular}

Different letters $(\mathrm{a}, \mathrm{b}, \mathrm{c}, \mathrm{d})$ indicate statistically significant $(p<0.05)$ differences between not heated and heated samples.

The degradation of chlorophylls during heating cycles can be explained by the fact that these compounds are sensitive to higher temperatures as they are to light exposure $[45,46]$. Chlorophylls occur in cold-pressed plant oils; they are removed in the refining process. 
The removal of chlorophylls is done due to the stabilization of refined oil and that is the reason for the better stability of refined oils in comparison to that of cold-pressed edible plant oils. The chlorophyll content in refined oils should be under $1 \mathrm{mg} / \mathrm{kg}$ due to the oil stabilization during storage and processing [47]. Based on our results, it can be observed that rapeseed oil is a significantly better source of chlorophyll than sunflower cold-pressed oil (Table 7). This finding is supported by previous studies too [44,48].

Carotenoid content in experimentally produced fortified oil samples did not unambiguously degrade during heating cycles. Although, statistically significant differences $(p<0.05)$ were observed, both decreased and increased carotenoid contents were measured during the three heating cycles. However, a clear pattern was not visible (Table 8).

Table 8. Carotenoid content in oil samples after repeated cycles of heating.

\begin{tabular}{|c|c|c|c|c|}
\hline Sample & $\begin{array}{l}\text { Without Heating } \\
(\mathrm{mg} / \mathrm{kg})\end{array}$ & $\begin{array}{l}\text { 1st Heating } \\
(\mathrm{mg} / \mathrm{kg})\end{array}$ & $\begin{array}{l}\text { 2nd Heating } \\
\text { (mg/kg) }\end{array}$ & $\begin{array}{l}\text { 3rd Heating } \\
\text { (mg/kg) }\end{array}$ \\
\hline$S$ & $11.67 \pm 0.35^{a}$ & $12.41 \pm 0.01^{b}$ & $12.61 \pm 0.06^{b c}$ & $13.10 \pm 0.06^{\mathrm{c}}$ \\
\hline $\mathrm{R}$ & $88.75 \pm 0.21^{a}$ & $87.82 \pm 0.18^{b}$ & $89.24 \pm 0.06^{c}$ & $83.90 \pm 0.05^{\mathrm{d}}$ \\
\hline Sss1 & $11.67 \pm 0.07^{\mathrm{a}}$ & $15.73 \pm 0.02^{b}$ & $14.35 \pm 0.02^{c}$ & $15.75 \pm 0.03^{b}$ \\
\hline Sss5 & $11.48 \pm 0.01^{\mathrm{a}}$ & $15.73 \pm 0.09^{b}$ & $20.85 \pm 0.07^{c}$ & $14.01 \pm 0.07^{\mathrm{d}}$ \\
\hline Rss1 & $88.44 \pm 0.11^{a}$ & $86.80 \pm 0.11^{b}$ & $85.24 \pm 0.10^{c}$ & $81.74 \pm 0.12^{\mathrm{d}}$ \\
\hline Rss5 & $85.63 \pm 0.09^{a}$ & $94.87 \pm 0.24^{b}$ & $89.69 \pm 0.40^{c}$ & $91.85 \pm 0.82^{\mathrm{c}}$ \\
\hline Schs1 & $11.16 \pm 0.01^{a}$ & $11.54 \pm 0.11 \mathrm{ac}$ & $10.79 \pm 0.01^{b}$ & $11.79 \pm 0.01^{\mathrm{c}}$ \\
\hline Schs5 & $11.38 \pm 0.02^{a}$ & $11.67 \pm 0.06^{b}$ & $13.36 \pm 0.05^{c}$ & $11.44 \pm 0.11^{\mathrm{a}}$ \\
\hline Rchs1 & $87.52 \pm 0.00^{a}$ & $90.88 \pm 0.35^{b}$ & $84.78 \pm 0.10^{\mathrm{c}}$ & $82.81 \pm 0.04^{d}$ \\
\hline Rchs5 & $87.92 \pm 0.18^{a}$ & $85.80 \pm 0.09^{b}$ & $83.53 \pm 0.16^{c}$ & $81.32 \pm 0.18^{\mathrm{d}}$ \\
\hline Sso1 & $11.60 \pm 0.06^{\mathrm{a}}$ & $10.87 \pm 0.01^{b}$ & $12.01 \pm 0.05^{c}$ & $11.45 \pm 0.04^{\mathrm{d}}$ \\
\hline Sso5 & $10.93 \pm 0.01^{\mathrm{a}}$ & $12.75 \pm 0.06^{b}$ & $14.34 \pm 0.02^{c}$ & $14.75 \pm 0.02^{\mathrm{d}}$ \\
\hline Rso1 & $106.72 \pm 0.18^{a}$ & $85.13 \pm 0.10^{b}$ & $83.55 \pm 0.05^{c}$ & $80.05 \pm 0.11^{\mathrm{d}}$ \\
\hline Rso5 & $85.33 \pm 0.20^{a}$ & $82.76 \pm 0.23^{b}$ & $83.27 \pm 0.04^{c}$ & $75.84 \pm 0.10^{\mathrm{d}}$ \\
\hline Scho1 & $11.42 \pm 0.01^{\mathrm{a}}$ & $11.41 \pm 0.01^{\mathrm{a}}$ & $10.91 \pm 0.00^{b}$ & $10.93 \pm 0.03^{b}$ \\
\hline Scho5 & $12.98 \pm 0.04^{\mathrm{a}}$ & $12.46 \pm 0.00^{b}$ & $12.26 \pm 0.04^{\mathrm{c}}$ & $14.23 \pm 0.06^{\mathrm{d}}$ \\
\hline Rcho1 & $86.29 \pm 0.11^{a}$ & $84.67 \pm 0.08^{b}$ & $82.93 \pm 0.04^{c}$ & $81.36 \pm 0.08^{\mathrm{d}}$ \\
\hline Rcho5 & $88.59 \pm 0.06^{a}$ & $84.78 \pm 0.13^{b}$ & $83.79 \pm 0.09^{c}$ & $80.31 \pm 0.06^{\mathrm{d}}$ \\
\hline
\end{tabular}

$\overline{\text { Different letters }(a, b, c, d)}$ indicate statistically significant $(p<0.05)$ differences between not heated and heated samples.

Previous studies indicated mainly that temperatures over $180{ }^{\circ} \mathrm{C}$ affected visual changes in rapeseed cold-pressed oils. The changes occurred usually due to the degradation of chlorophylls and carotenoids [49]. The degradation of carotenoids can be increased in the presence of hydroperoxides, since hydroperoxides affect carotenoid degradation to hydroxyl- and epoxycarotenes [44]. The measured increase of carotenoid content in some samples can be the result of the disruption of carotenoid-protein complexes. Carotenoidprotein complexes could have persisted in cold-pressed oils before thermal treatment since these oils were not stabilized through refining processes [50].

\section{Conclusions}

The research unambiguously showed that the thermal treatment of cold-pressed oils fortified with chia and sesame seeds and oils can be detected by sensory analysis. The sensory parameters that distinguished the most evaluated samples were oxidized flavor and burnt flavor. Oxidized flavor was noticed mainly after the second thermal treatment, whereas burnt flavor was apparent after the third thermal treatment. No visible changes of color were noticed after three thermal treatments of the fortified cold-pressed oils. Until the second thermal treatment, the overall pleasantness of all fortified cold-pressed oils was still acceptable. Chemical analysis of experimentally produced fortified cold-pressed oils did not show a clear pattern related to changes during thermal treatment cycles. However, the most significant changes were observed in the peroxide value increase and chlorophyll 
content decrease during heating cycles. The study indicated that culinary use of such products should be limited to only one thermal treatment since sensory and chemical changes occur after repeated heating.

Author Contributions: Conceptualization, methodology and software: A.T. and D.D.; validation: B.T., A.T. and D.D.; investigation: A.T., D.D. and S.J.; resources: B.T. and D.D.; writing—original draft preparation: A.T. and D.D.; writing-review and editing: A.T., D.D., P.K. and B.T.; supervision: B.T.; project administration: D.D. and A.T. All authors have read and agreed to the published version of the manuscript.

Funding: This research was funded by project FVHE/Tremlová/ITA2021 from the University of Veterinary Sciences Brno, Czech Republic.

Institutional Review Board Statement: Not applicable.

Informed Consent Statement: Not applicable.

Conflicts of Interest: The authors declare no conflict of interest.

\section{References}

1. Rusinek, R.; Siger, A.; Gawrysiak-Witulska, M.; Rokosik, E.; Malaga-Toboła, U.; Gancarz, M. Application of an electronic nose for determination of pre-pressing treatment of rapeseed based on the analysis of volatile compounds contained in pressed oil. Int. J. Food Sci. Technol. 2020, 55, 2161-2170. [CrossRef]

2. Konuskan, D.B.; Arslan, M.; Oksuz, A. Physicochemical properties of cold pressed sunflower, peanut, rapeseed, mustard and olive oils grown in the Eastern Mediterranean region. Saudi J. Biol. Sci. 2019, 26, 340-344. [CrossRef]

3. McDowell, D.; Elliott, C.T.; Koidis, A. Characterization and comparison of UK, Irish, and French cold pressed rapeseed oils with refined rapeseed oils and extra virgin olive oils. Eur. J. Lipid Sci. Technol. 2017, 119, 1600327. [CrossRef]

4. Gracka, A.; Raczyk, M.; Hradecký, J.; Hajslova, J.; Jeziorski, S.; Karlovits, G.; Michalak, B.; Bakowska, N.; Jeleń, H. Volatile compounds and other indicators of quality for cold-pressed rapeseed oils obtained from peeled, whole, flaked, and roasted seeds. Eur. J. Lipid Sci. Technol. 2017, 119, 1600328. [CrossRef]

5. Brühl, L.; Matthäus, B. Sensory assessment of virgin rapeseed oils. Eur. J. Lipid Sci. Technol. 2008, 110, 608-610. [CrossRef]

6. Rusinek, R.; Jeleń, H.; Malaga-Toboła, U.; Molenda, M.; Gancarz, M. Influence of Changes in the Level of Volatile Compounds Emitted during Rapeseed Quality Degradation on the Reaction of MOS Type Sensor-Array. Sensors 2020, 20, 3135. [CrossRef] [PubMed]

7. Febrianto, N.A.; Yang, T.A. Producing High Quality Edible Oil by using Eco-Friendly Technology: A Review. Adv. J. Food Sci. Technol. 2011, 3, 317-326.

8. Parker, T.D.; Adams, D.A.; Zhou, K.; Harris, M.; Yu, L. Fatty acid composition and oxidative stability of cold-pressed edible seed oils. J. Food Sci. 2003, 68, 1240-1243. [CrossRef]

9. Tsaknis, J.; Lalas, S. Stability During Frying of Moringa oleifera Seed Oil Variety "Periyakulam 1". J. Food Compos. Anal. 2002, 15, 79-101. [CrossRef]

10. Romero, A.; Cuesta, C.; Sanchez-Muniz, F.J. Does frequent replenishment with fresh monoenoic oil permit the frying of potatoes indefinitely? J. Agric. Food Chem. 1999, 47, 1168-1173. [CrossRef]

11. Redondo-Cuevas, L.; Castellano, G.; Torrens, F.; Raikos, V. Revealing the relationship between vegetable oil composition and oxidative stability: A multifactorial approach. J. Food Compos. Anal. 2018, 66, 221-229. [CrossRef]

12. Ramadan, M.F. Healthy blends of high linoleic sunflower oil with selected cold pressed oils: Functionality, stability and antioxidative characteristics. Ind. Crop. Prod. 2013, 43, 65-72. [CrossRef]

13. Rudziñska, M.; Korczak, J.; Wasowicz, E. Changes in phytosterols and their oxidation products during frying of French fries in rapeseed oil. Pol. J. Food Nutr. Sci. 2005, 14, 381-387.

14. Kmiecik, D.; Korczak, J.; Rudzińska, M.; Michałowska, A.G.; Hęś, M. Stabilization of phytosterols in rapeseed oil by natural antioxidants during heating. Eur. J. Lipid Sci. Technol. 2009, 111, 1124-1132. [CrossRef]

15. Romankiewicz, D.; Hassoon, W.H.; Cacak-Pietrzak, G.; Sobczyk, M.; Wirkowska-Wojdyla, M.; Ceglinska, A.; Dziki, D. The effect of chia seeds (Salvia hispanica L.) addition on quality and nutritional value of wheat bread. J. Food Qual. 2017, 1, 7352631. [CrossRef]

16. Marineli, R.S.; Moraes, E.A.; Lenquiste, S.A.; Godoy, A.T.; Eberlin, M.N.; Maróstica, M.R., Jr. Chemical characterization and antioxidant potential of Chilean chia seeds and oil (Salvia hispanica L.). LWT Food Sci. Technol. 2014, 59, 1304-1310. [CrossRef]

17. Mohammed, F.; Abdulwali, N.; Guillaume, D.; Tenyang, N.; Ponka, R.; Al-Gadabi, K.; Bchitou, R.; Abdullah, A.H.; Naji, K.M. Chemical composition and mineralogical residence of sesame oil from plants grown in different Yemeni environments. Microchem. J. 2018, 140, 269-277. [CrossRef]

18. Wu, R.; Ma, F.; Zhang, L.; Li, P.; Li, G.; Zhang, Q.; Zhang, W.; Wang, X. Simultaneous determination of phenolic compounds in sesame oil using LC-MS/MS combined with magnetic carboxylated multi-walled carbon nanotubes. Food Chem. 2016, 204, 334-342. [CrossRef] 
19. Namiki, M. Nutraceutical functions of sesame: A review. Crit. Rev. Food Sci. Nutr. 2007, 47, 651-673. [CrossRef]

20. Bendini, A.; Barbieri, S.; Valli, E.; Buchecker, K.; Canavari, M.; Toschi, T.G. Quality evaluation of cold pressed sunflower oils by sensory and chemical analysis. Eur. J. Lipid Sci. Technol. 2011, 113, 1375-1384. [CrossRef]

21. Mazzucchelli, R.; Guinard, J.X. Comparison of monadic and simultaneous sample presentation modes in a descriptive analysis of milk chocolate. J. Sens. Stud. 1999, 14, 235-248. [CrossRef]

22. International Organization for Standardization. Animal and Vegetable Fats and Oils_Determination of Peroxide Value-Iodometric (Visual) Endpoint Determination (ISO Standard No. 3960); International Organization for Standardization: Geneva, Switzerland, 2017.

23. International Organization for Standardization. Animal and Vegetable Fats and Oils-Determination of Acid Value and Acidity (ISO Standard No. 660); International Organization for Standardization: Geneva, Switzerland, 2009.

24. Kraljić, K.; Škevin, D.; Pospíšil, M.; Obranović, M.; Neđeral, S.; Bosolt, T. Quality of rapeseed oil produced by conditioning seeds at modest temperatures. J. Am. Oil Chem. Soc. 2013, 90, 589-599. [CrossRef]

25. Multari, S.; Marsol-Vall, A.; Heponiemi, P.; Suomela, J.P.; Yang, B. Changes in the volatile profile, fatty acid composition and other markers of lipid oxidation of six different vegetable oils during short-term deep-frying. Food Res. Int. 2019, 122, 318-329. [CrossRef]

26. Nayak, P.K.; Dash, U.; Rayaguru, K.; Krishnan, K.R. Physio-Chemical Changes During Repeated Frying of Cooked Oil: A Review. J. Food Biochem. 2015, 40, 371-390. [CrossRef]

27. Khan, M.; Asha, M.R.; Bhat, K.K.; Khatoon, S. Studies on chemical and sensory parameters of coconut oil and its olein blends with sesame oil and palm olein during wheat flour-based product frying. J. Food Sci. Technol. 2011, 48, 175-182. [CrossRef]

28. Giuffrè, A.M.; Capocasale, M.; Zappia, C.; Poiana, M. Influence of high temperature and duration of heating on the sunflower seed oil properties for food use and biodiesel production. J. Oleo Sci. 2017, 66, 1193-1205. [CrossRef]

29. Xu, X.Q.; Tranch, P.M.; White, K.; Salisbury, P. Chemical and physical analysis and sensory evaluation of sixdeep frying oil. J. Am. Oil Chem. Soc. 1999, 76, 1091-1099. [CrossRef]

30. Lawless, H.T.; Heymann, H. Sensory Evaluation of Food: Principles and Practices; Springer Science \& Business Media: Berlin, Germany, 2020.

31. Aparicio-Ruiz, R.; Barbieri, S.; Gallina Toschi, T.; García-González, D.L. Formulations of Rancid and Winey-Vinegary Artificial Olfactory Reference Materials (AORMs) for Virgin Olive Oil Sensory Evaluation. Foods 2020, 9, 1870. [CrossRef]

32. Wiking, L.; Løkke, M.M.; Kidmose, U.; Sundekilde, U.K.; Dalsgaard, T.K.; Larsen, T.; Feilberg, A. Comparison between novel and standard methods for analysis of free fatty acids in milk-Including relation to rancid flavour. Int. Dairy J. 2017, 75, 22-29. [CrossRef]

33. Ravelli, D.; Matsuoka, C.R.; Della Modesta, R.C.; Vieira, T.M.F.; Regitano-de Arce, M.A.B. Determination of deep frying soybean oil disposal point by a sensory method. J. Am. Oil Chem. Soc. 2010, 87, 515-520. [CrossRef]

34. Tarmizi, A.H.; Niranjan, K.; Gordon, M. Physicochemical changes occurring in oil when atmospheric frying is combined with post frying vacuum application. Food Chem. 2013, 136, 902-908. [CrossRef]

35. Rehab, F.M.A.; El-Anany, A. Physicochemical studies on sunflower oil blended with cold pressed tiger nut oil during deep frying process. Grasas Y Aceites 2012, 63, 455-465. [CrossRef]

36. Bakhtiary, D. Sensory qualities of sesame oil, palm olein and the blend of them during frying of potato chips. Tech. J. Eng. Appl. Sci. 2014, 4, 48-52.

37. Ekwenye, U.N. Chemical characteristics of palm oil biodeterioration. Biokemistri 2006, 18, 141-149. [CrossRef]

38. Różańska, M.B.; Kowalczewski, P.Ł.; Tomaszewska-Gras, J.; Dwiecki, K.; Mildner-Szkudlarz, S. Seed-Roasting Process Affects Oxidative Stability of Cold-Pressed Oils. Antioxidants 2019, 8, 313. [CrossRef]

39. Tynek, M.; Pawlowicz, R.; Gromadzka, J.; Tylingo, R.; Wardencki, W.; Karlovits, G. Virgin rapeseed oils obtained from different rape varieties by cold pressed method-Their characteristics, properties, and differences. Eur. J. Lipid Sci. Technol. 2012, 114, 357-366. [CrossRef]

40. Codex Alimentarius. Codex Standard for Edible Fats and Oils Not Covered by Individual Standards (CODEX STAN 19-1981, Rev. 2-1999); FAO/WHO: Rome, Italy, 1999.

41. Bilancia, M.T.; Caponio, F.; Sikorska, E.; Pasqualone, A.; Summo, C. Correlation of triacylglycerol oligopolymers and oxidised triacylglycerols to quality parameters in extra virgin olive oil during storage. Food Res. Int. 2007, 40, 855-861. [CrossRef]

42. Mahesar, S.A.; Sherazi, S.T.H.; Khaskheli, A.R.; Kandhro, A.A.; Uddin, S. Analytical approaches for the assessment of free fatty acids in oils and fats. Anal. Methods 2014, 6, 4956-4963. [CrossRef]

43. Almeida, D.T.D.; Viana, T.V.; Costa, M.M.; Silva, C.D.S.; Feitosa, S. Effects of different storage conditions on the oxidative stability of crude and refined palm oil, olein and stearin (Elaeis guineensis). Food Sci. Technol. 2018, 39, 211-217. [CrossRef]

44. Choe, E.; Min, D.B. Mechanisms and factors for edible oil oxidation. Compr. Rev. Food Sci. Food Saf. 2006, 5, 169-186. [CrossRef]

45. Lee, E.; Ahn, H.; Choe, E. Effects of light and lipids on chlorophyll degradation. Food Sci. Biotechnol. 2014, 23, 1061-1065. [CrossRef]

46. Rasul, H.; İnanc, A. Thermal Stability of Chlorophyll Pigments in Virgin Olive Oil. KSÜ Doğa Bilimleri Derg. 2014, 17, 34-40. [CrossRef]

47. Szydłowska-Czerniak, A.; Tułodziecka, A.; Momot, M.; Stawicka, B. Physico-chemical, Antioxidative and Sensory Properties of Refined Rapeseed Oils. J. Am. Oil Chem. Soc. 2019, 96, 405-419. [CrossRef] 
48. Ghazani, S.M.; García-Llatas, G.; Marangoni, A.G. Minor constituents in canola oil processed by traditional and minimal refining methods. J. Am. Oil Chem. Soc. 2013, 90, 743-756. [CrossRef]

49. Saleem, M.; Ahmad, N. Characterization of canola oil extracted by different methods using fluorescence spectroscopy. PLoS ONE 2018, 13, e0208640. [CrossRef]

50. Lyu, Y.; Bi, J.; Chen, Q.; Li, X.; Lyu, C.; Hou, H. Color, Carotenoids, and Peroxidase Degradation of Seed-Used Pumpkin Byproducts as Affected by Heat and Oxygen Content During Drying Process. Food Bioprocess. Technol. 2020, 13, 1929-1939. [CrossRef] 